\title{
Are precipitation anomalies associated with aerosol variations over eastern China?
}

\author{
Xiangde Xu ${ }^{1}$, Xueliang Guo ${ }^{1,2}$, Tianliang Zhao ${ }^{3}$, Xingqin $\mathrm{An}^{1}$, Yang Zhao ${ }^{1}$, Jiannong Quan ${ }^{4}$, Fei Mao ${ }^{1}$, Yang Gao ${ }^{5}$, \\ Xinghong Cheng ${ }^{1}$, Wenhui Zhu ${ }^{1}$, and Yinjun Wang ${ }^{1}$ \\ ${ }^{1}$ State Key Laboratory of Severe Weather (LASW), Chinese Academy of Meteorological Sciences, Beijing, 100081, China \\ ${ }^{2}$ Key Laboratory for Cloud Physics, Chinese Academy of Meteorological Sciences, Beijing, 100081, China \\ ${ }^{3}$ Collaborative Innovation Center on Forecast and Evaluation of Meteorological Disasters, Key Laboratory for \\ Aerosol-Cloud-Precipitation of China Meteorological Administration, Nanjing University of Information Science \& \\ Technology, Nanjing, 210044, China \\ ${ }^{4}$ Institute of Urban Meteorology, Chinese Meteorological Administration, Beijing, 100089, China \\ ${ }^{5}$ Beijing Weather Modification Office, Beijing, 100089, China
}

Correspondence to: Tianliang Zhao (tlzhao@nuist.edu.cn) and Xueliang Guo (guoxl@camscma.cn)

Received: 21 November 2016 - Discussion started: 12 January 2017

Revised: 14 May 2017 - Accepted: 20 May 2017 - Published: 30 June 2017

\begin{abstract}
In eastern China (EC), the strong anthropogenic emissions deteriorate the atmospheric environment, building a south-north zonal distribution of high aerosols harbored by the upstream Tibetan and Loess plateaus in China. This study climatologically analyzed the interannual variability in precipitation with different intensities in association with aerosol variations over the EC region from 1961 to 2010 by using precipitation and visibility data from more than 50 years and aircraft and surface aerosol data from recent years in China, and the impacts of aerosol variations on interannual variability in the intensity of precipitation events and their physical causes are investigated. We found that the frequency of light rain has significantly decreased and the occurrence of rainstorms, especially severe rainstorms, has significantly increased over recent decades. The extreme precipitation events presented an interannual variability pattern similar to that of the frequent haze events over EC. Accompanied by the frequent haze events in EC, light rain frequency significantly decreased and extremely heavy precipitation events have occurred more frequently. During the 1980s, the regional precipitation trends in EC showed an obvious transform from more light rain to more extreme rainstorms. The running correlation analysis of interdecadal variation further verified that the correlation between the increasing aerosols and frequencies of abnormal precipitation events tended to be more significant in EC. The correlation between atmospheric
\end{abstract}

visibility and low cloud amounts, which are both closely related to aerosol concentrations, was positive in the north and negative in the south, and the spatial distribution of the variability in regional rainstorm frequency was positive in the south and negative in the north. After the 1990s, the visibility in summer season deteriorated more remarkably, light rain frequency decreased noticeably, and rainstorms and extraordinarily heavy rainfall occurred more frequently. There were significant differences in the interdecadal variation trends in light rain and rainstorm events between the highly aerosolpolluted area in EC and the relatively clean area on the western plateaus of China. The aircraft measurements over EC confirmed that the diameters of cloud droplets decreased under high aerosol concentration conditions, thereby inhibiting weak precipitation process.

\section{Introduction}

In the context of global warming, regional precipitation tends to have more complex temporal and spatial distribution patterns. The variations in precipitation could be reflected by the different grades of precipitation, and even by frequency changes in extreme precipitation events (Lau and Wu, 2007). Precipitation is not only influenced by atmospheric circulation related to land-sea discrepancy and land-sea water 
vapor exchange but also by local cloud microphysical processes. Atmospheric aerosols might increase cloud droplet number concentrations, change cloud lifetime, and modify precipitation (Khain et al., 2005; Rosenfeld et al., 2007, 2008; Stevens and Feingold, 2009; Fan et al., 2013). Aerosols might also change the Asian monsoon system (Bollasina et al., 2011). The interaction of aerosols with cloud and precipitation is still an important issue with large uncertainties for climate change (IPCC, 2013).

Since the mid-1980s, China has been experiencing rapid development in industry and agriculture. As a result, a huge amount of anthropogenic emissions and biomass burning have increasingly released particulate matter into the atmosphere. There was no obvious change in annual precipitation in China, but the extremely heavy rainfall area, mainly in eastern China (EC), has expanded (Zhai et al., 1999). However, the regional annual precipitation, summer precipitation, and extreme precipitation events have obvious rising tendencies in the middle and lower Yangtze River basin of EC (Wang and Zhou, 2005).

The numerical simulations also showed that the increase in aerosols could decrease the summer convective precipitation with an intensity under $30 \mathrm{~mm} \mathrm{~h}^{-1}$ and increase summer strong convective precipitation with an intensity above $30 \mathrm{~mm} \mathrm{~h}^{-1}$ in China (Guo et al., 2014). With a rapid increase in aerosols, not only light rain over wide areas could decrease but also extremely heavy local rain could be triggered, inducing frequent flooding (Guo et al., 2014; Fan et al., 2015). Light rain tended to decrease and at the same time the extremely heavy precipitation tended to increase in EC (Choi et al., 2008; Qian et al., 2007, 2009). This phenomenon might be evidence of climate variability connected to global warming together with increased emissions of anthropogenic aerosols.

The previous investigations of this issue primarily focused on limited cases with large discrepancies (Rosenfeld et al., 2007, 2008; Stevens and Feingold, 2009; Li et al., 2011; Fan et al., 2013). The climatic forcing of aerosols on precipitation in a large-scale region and its physical causes have been poorly understood. The long-term visibility data can be used to climatologically assess the air quality change (Wang et al., 2009; Che et al., 2009; Xia et al., 2006), as the atmospheric visibility is a good indicator of air pollutant levels in the environmental atmosphere (Zhao et al., 2016). By using precipitation and visibility data from a 50 -year period and aircraft and surface aerosol observational data from recent years in China, the climatic impacts of aerosols on interannual variability in precipitation intensity and its physical links were investigated in this study. In addition, the high aerosol concentrations are accumulated in the north-south direction over EC in connection with the terrain effect of the Tibetan Plateau (TP) and the Loess Plateau in China (Xu et al., 2016).The polluted EC region and the clean plateaus in China may be the ideal places to identify the climate forcing of aerosols by comparing the interannual variation trends in precipitation intensity for exploring the relationship between precipitation anomalies and aerosol variations.

\section{Data}

In this study, we used the classifications extraordinary storm, large rainstorm, rainstorm, large rain, moderate rain and light rain with daily precipitation $>200$ and ranging between 100 and 200, 50 and 100,25 and 50, 10 and 25, and 0.1 and $10 \mathrm{~mm}$, respectively. The monthly data of precipitation events of extraordinary storm, large rainstorm, rainstorm, large rain, moderate rain, and light rain from 601 stations in China from 1961 to 2010 were adopted from the National Meteorological Information Center of the China Meteorological Administration. In addition, the meteorological and environmental data including haze days, daily visibility and low cloud cover in 1961-2010 as well as the daily $\mathrm{PM}_{2.5}$ data of 946 stations in 2013-2014 in China were also used in this study.

In order to analyze the regional variations in aerosols over $\mathrm{EC}$, we adopt the equivalent visibility by excluding the influence of natural factors (Rosenfeld et al., 2007) on the observed visibility based on the meteorological data in 19612010. The equivalent visibility was corrected VIS (dry) based on the following Eq. (1) under relative humidity from 40 to $90 \%$.

$$
\frac{\mathrm{VIS}}{\mathrm{VIS}(\text { dry })}=0.26+0.4285 \log (100-\mathrm{RH})
$$

The vertical changes in aerosol and cloud droplet size were comprehensively analyzed based on the aerosol-cloud data observed from aircraft flights over Beijing and its surrounding regions during 2008-2010. The flight-observed clouds were mainly stratus, stratocumulus and cumulus, and the maximum detection altitude was $7000 \mathrm{~m}$. There were 40 flights carried out in $2-6 \mathrm{~h}$ before precipitation. The flight area and tracks were shown in Fig. 1. The passive cavity aerosol spectrometer probe (PCASP-200, DMT Co.) was used for observing aerosol particle size of $0.1-0.3 \mu \mathrm{m}$. The cloud, aerosol and precipitation spectrometer (CAPS, DMT Co.) was used for observing cloud droplets of 0.6$50 \mu \mathrm{m}$. The probes were returned to the DMT for standard calibration before starting measurements in each year. In addition, the probes were calibrated using spheres of polystyrene latex (PSL) from Duke Scientific Corporation for each month. Considering the influence of cloud droplets on aerosol probing, the averaged aerosol concentration below $300 \mathrm{~m}$ of cloud base was calculated to represent aerosol concentration in clouds. The cloud droplet measurements were made within clouds at 100 height intervals. The data were processed into two or more samples when the clouds were multiply layered. 


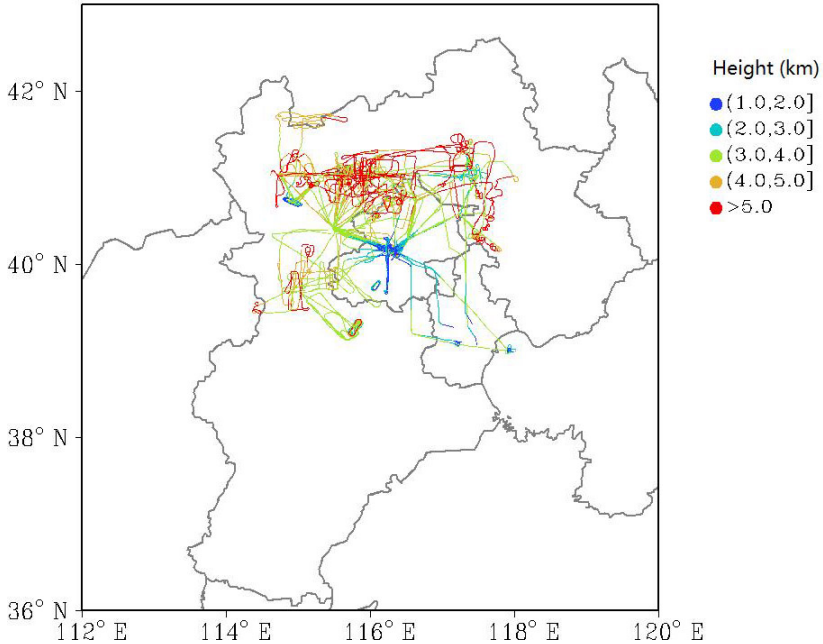

Figure 1. Area and tracks of 40 aircraft flights carried out in Beijing and its surrounding regions during aerosol-cloud experiments from 2008 to 2010 by the Beijing Weather Modification Office, China.

\section{Haze distributions in eastern China}

Due to the influence of the terrain on the typical westerly, the air flowing from the windward plateaus descended between about 110 and $125^{\circ} \mathrm{E}$ (panel (a) in Fig. 2). Accompanying this strong downward current were weak winds in the nearsurface layers. The wind condition leads to accumulating air pollutants in EC. The weak wind and downward current areas coincide well with the centers of frequent haze events in EC (panel (b) in Fig. 2). The frequent haze pollution over EC is associated with the harbor effect of the topography under specific meteorological conditions that trap air pollutants (Xu et al., 2016). EC is climatologically a region with frequent haze events over recent decades, and high aerosol pollution could exert an impact on the regional variation in precipitation.

\section{Change trends in precipitation intensity}

The interannual variation in precipitation events with various intensities of light rain, moderate rain, heavy rain, rainstorm, large rainstorm and extraordinary rainstorm over EC were comparatively analyzed in Fig. 3. Regionally averaged over EC, the trends in light rain frequency significantly decreased, while the events of rainstorms, including large and extraordinary storms, increased significantly (Fig. 3a). However, the moderate rain frequency trend slightly declined, and the interannual change trend of large rain frequency was not significant (Fig. 3a). Especially since the 1980s, the extremely heavy precipitation events have become more frequent, showing frequent occurrences of disastrous rainstorm along with frequent haze in EC. Overall, extreme rain-

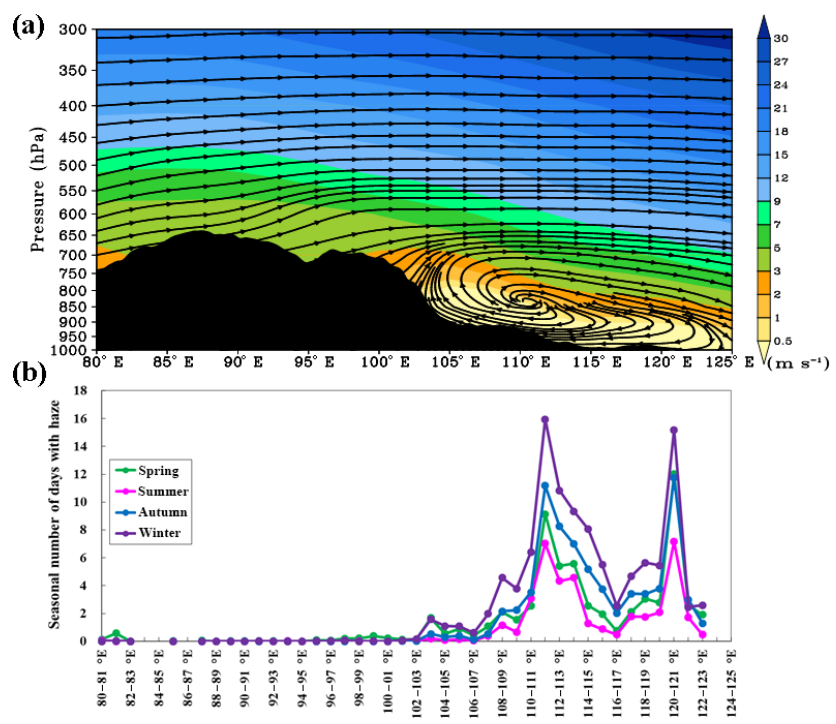

Figure 2. Cross sections of vertical circulations illustrated by stream lines (a) with the horizontal wind speed ( $\mathrm{m} \mathrm{s}^{-1}$; color contours) and zonal variations in annual haze event frequency (b) at $27-$ $41^{\circ} \mathrm{N}$ averaged in spring, summer, autumn and winter over $1961-$ 2012. Note that near-surface vertical and horizontal winds are not illustrated well here due to north-south variations in the terrain and approximation of the location of the plateaus (black shaded area) in panel (a). All fields are for the annual averages.

storm events were on the rise, but light rain tended to decline significantly. In contrast, stations on the TP with an altitude $>4000 \mathrm{~m}$, a relative clean area in China, were selected for a statistical analysis of interannual variation trends in light rain frequency. The characteristic of the decreased trend in light rain frequency has not been significant in the TP over recent decades (Fig. 3b), which could imply that aerosol anomalies restrain light rain frequency over EC.

\section{Regional changes in precipitation events, haze and visibility}

We calculated the trends in interannual variations in precipitation and visibility at all the sites in China (Fig. 4). The areas with negative trends in light rain frequency matched quite well with the areas of negative trends in visibility frequency and positive trends in haze frequency in EC (Fig. 4ac). The light rain frequency reduction in China was closely associated with the enhancement of aerosol levels in the atmosphere (Qian et al., 2009).

It is noteworthy that the negative trend areas of light rain covered the most sites in EC (Fig. 4c). This might also be closely related to temporal and spatial variations in the East Asian summer monsoon, which offered a suitable dynamic background for the effect of aerosols on clouds and precipitation. Figure 5a shows that a spatial distribution of the trends in rainstorm frequency was positive in the south and negative 

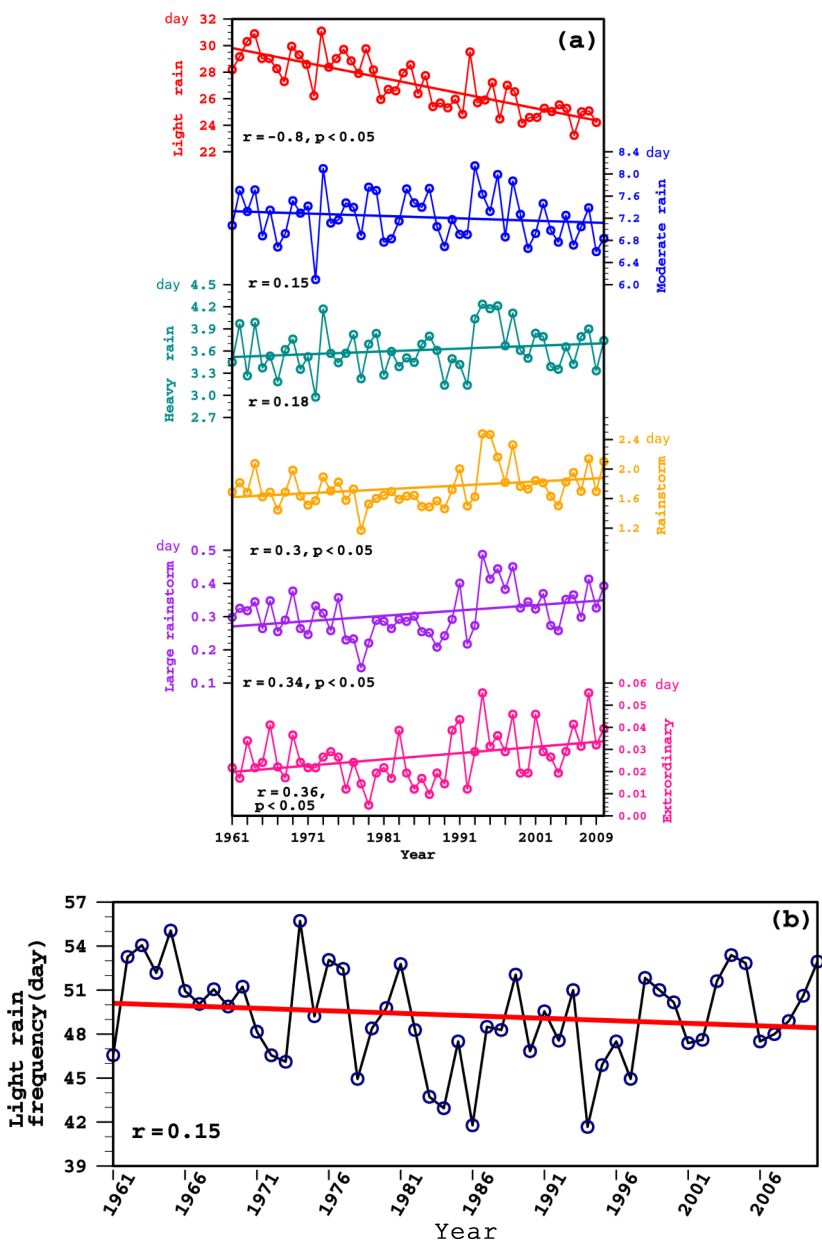

Figure 3. Interannual variations with their anomalies (broken lines) and trends (straight lines) in (a) various precipitation intensities in the high aerosol concentration area in the EC region and (b) light rain in the relatively clean area of the Tibetan Plateau.

in the north in summer during 1961-2010, while the correlations between visibility and low-level cloud amount were distributed as positive in the north and negative in the south in EC during 1961-2010 (Fig. 5b), indicating that the effect of aerosols on summer convective precipitation was more obvious in the southern part than in the northern part of EC.

There were obvious differences in the precipitation change rate of various precipitation intensities in the EC region (Fig. 6a), where the negative variability stations of light rain made up the majority (about $87.6 \%$ ), the positive variability stations of moderate rain were approximately equal to the negative ones (about $51 \%$ ) and the positive variability stations of large rain (about $71.3 \%$ ) were much more than the negative ones, indicating the reverse trend. The positive variability stations of rainstorm with daily precipitation $>50 \mathrm{~mm}$, including catastrophic rainstorms over $100 \mathrm{~mm}$ occupied the obvious majority (about $78.9 \%$ ). The increase in the anthropogenic aerosol particles in the atmo-
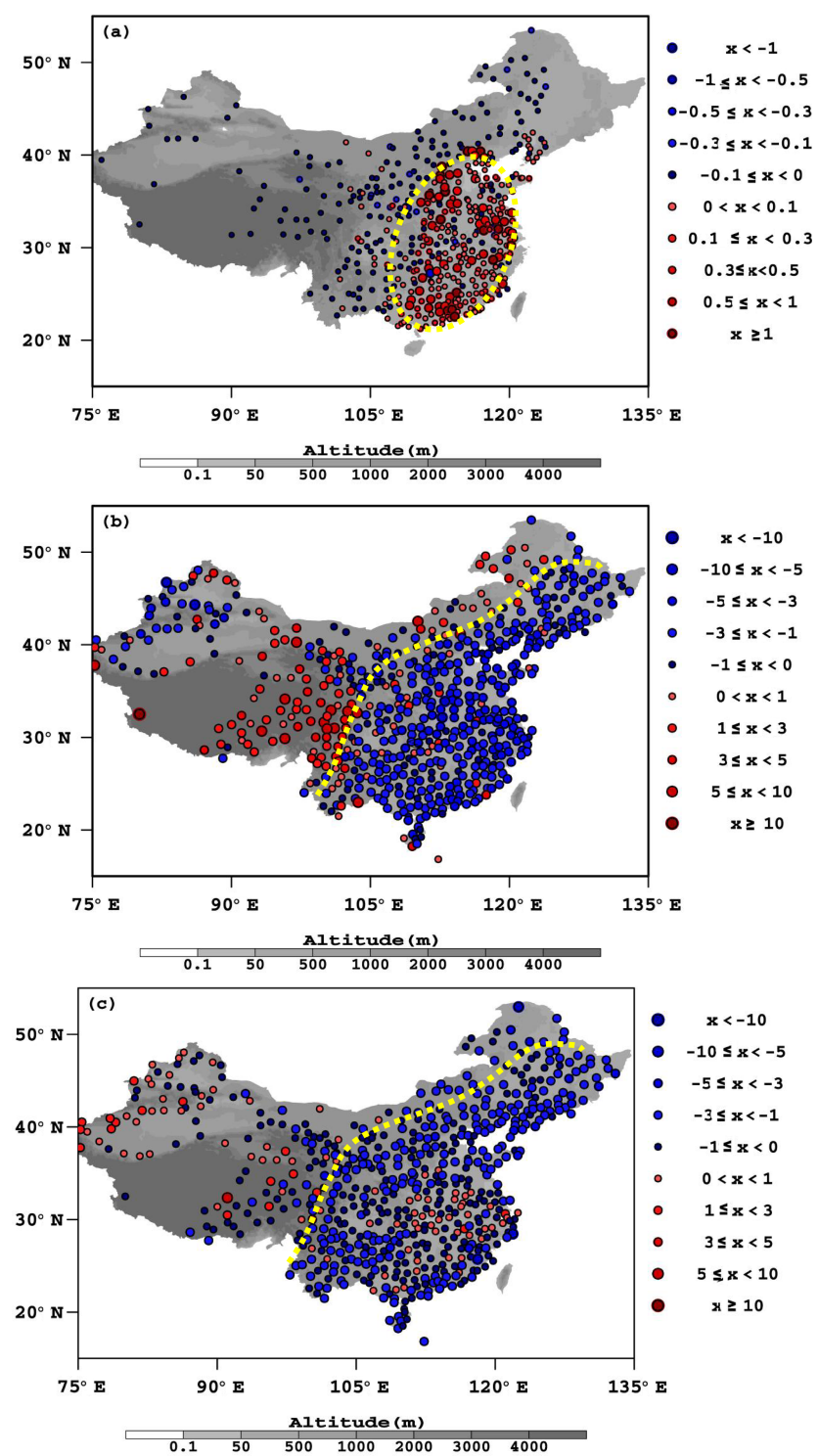

Figure 4. Distribution of interannual change trends (day per 10 years) in (a) haze frequency, (b) visibility and (c) light rain frequency in summer in mainland China in 1961-2010. The yellow dash lines mark the borders of frequent haze areas or the eastern borders of plateaus in China.

sphere may suppress light rain (Qian et al., 2009) and also enhance the rainstorm precipitation, with more frequent events in EC. The regional precipitation changed from less light rain to more heavy rain and even catastrophic rainstorms, along with the frequent haze pollution in EC.

Although precipitation events depended on dynamical and thermodynamic processes and a water vapor source in the atmosphere, the Albrecht effect of aerosol with increasing cloud droplet concentrations and decreasing cloud droplet size $i$ could suppress cloud precipitation processes and extend cloud lifetime. The extension of the cloud lifetime might save the potential for triggering the abnormal extreme se- 

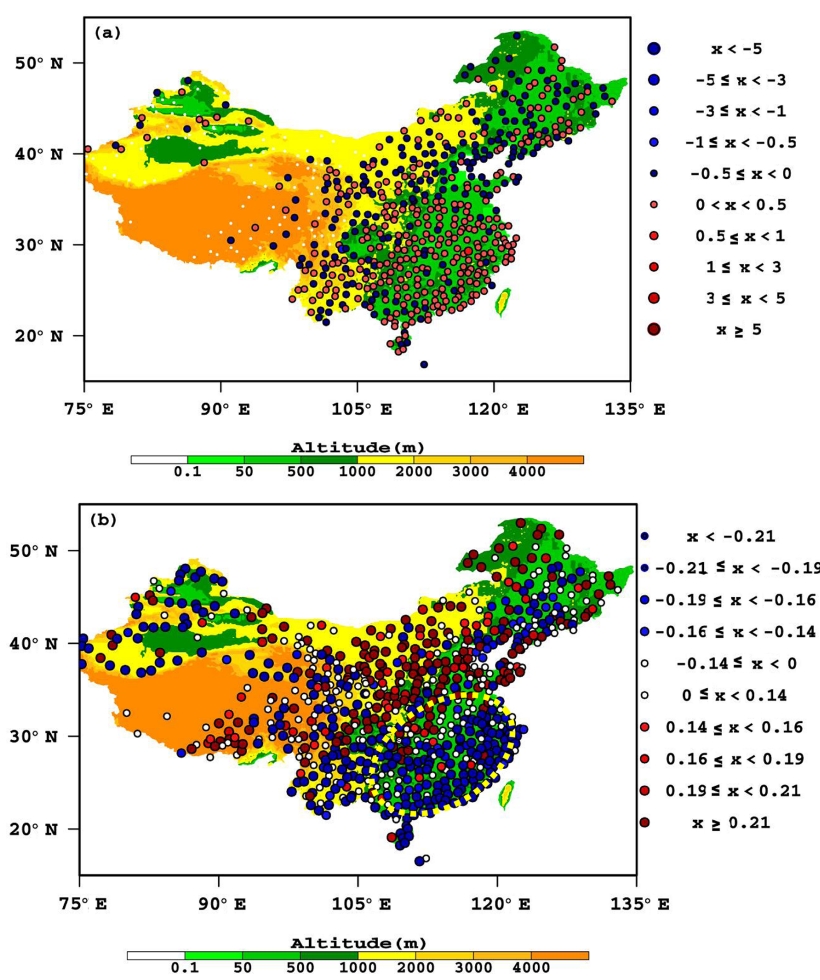

Figure 5. The spatial distributions of (a) trends (day per 10 years) in summertime rainstorm frequency over 1961-2010 in China and (b) correlation coefficients between visibility and low cloud amount in summer of 1961-2010, with the dashed yellow line marking the border of the negative correlation area.

vere precipitation events. This mechanism could partly explain the precipitation degrading from light rain to extreme severe events (Fig. 6a) in the polluted EC region. Furthermore, the region (west of $110^{\circ} \mathrm{E}$, south of $40^{\circ} \mathrm{N}$ ) of $\mathrm{TP}$, a relative clean area in western China, was selected as the reference area to comparatively analyze the effects of aerosol pollution on regional precipitation change in hazy EC. We calculated percentages of sites with negative frequency trends in light rain and positive trends in rainstorm events for all sites, with the positive and negative trends in haze over the EC and TP regions during the three interdecadal periods (19611980, 1971-2000 and 1981-2010) (Fig. 6b-c). Over the past 5 decades or more, light rain and rainstorms were receptively steady, declined and augmented in the polluted EC (Fig. 6b), while there were no obvious positive and negative variability trends in light rain and rainstorms in the clean TP region (Fig. 6c).

\section{Interannual anomalies between visibility and precipitation}

Figure 7 further verified the relation between interannual variability in regional visibility and precipitation in EC over recent years. Regionally averaged, less light rain events and
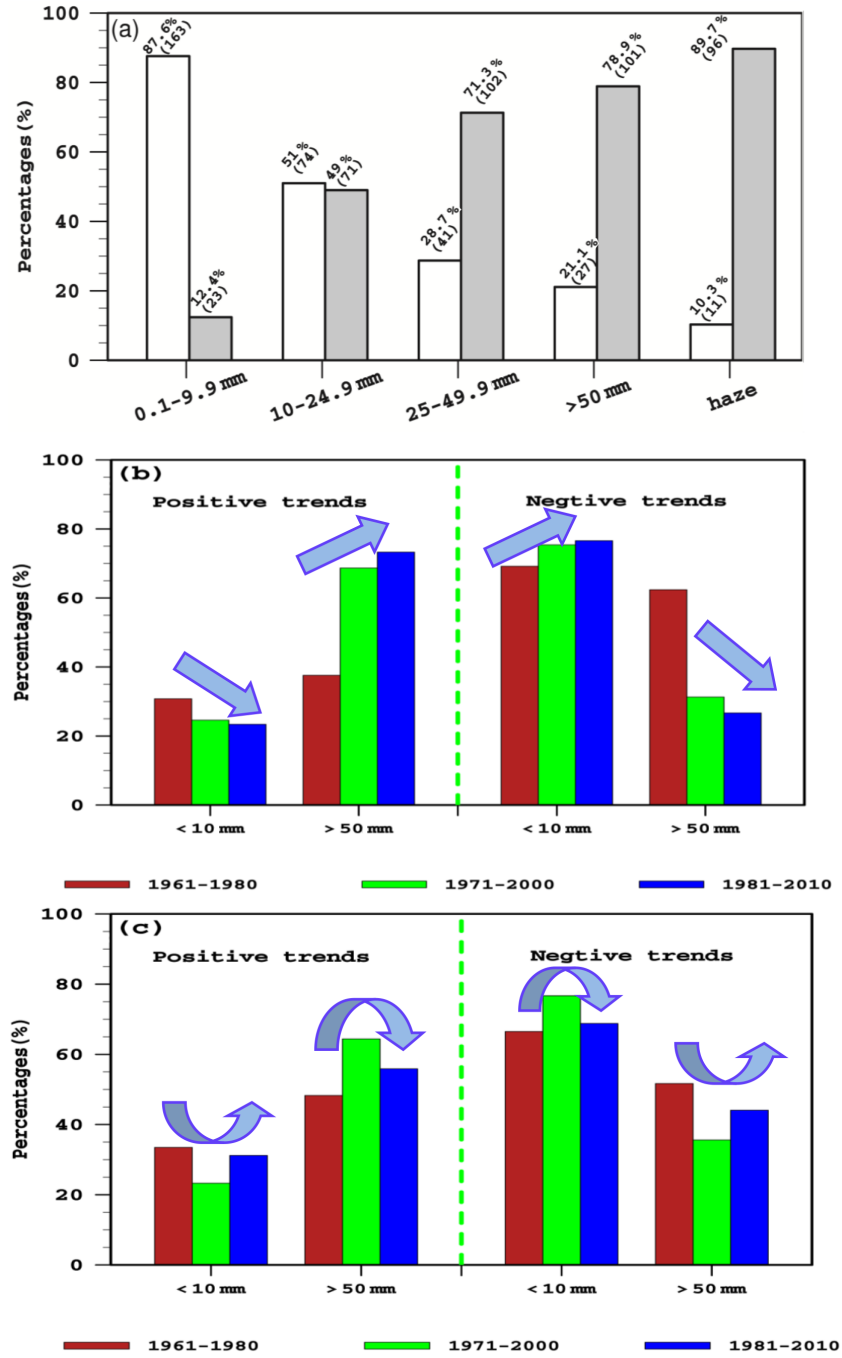

Figure 6. (a) Percentages of stations with positive and negative trends in number of day in various precipitation grades from 1961 to 2010 over the EC stations. The percentages of sites with negative frequency trends in light rain and positive trends in rainstorm events in total sites with positive (left side) and negative (right side) trends in haze over (b) the EC and (c) TP regions during the three interdecadal periods (1961-1980, 1971-2000 and 1981-2010). The arrows indicate the interdecadal change patterns.

more rainstorms varied significantly from year to year in association with enhanced aerosol levels with declining visibility over EC (Fig. 7a-d). Taking summer months (June, July and August) as examples, the 20-year running correlation coefficients of visibility and precipitation were presented in Fig. 7e. It is very interesting that the interannual variations in visibility and precipitation over EC evolved from positive correlations in the early 1960s to negative correlations in the 1970s and 1980s (Fig. 7e), reflecting the interannual variation in the aerosol and precipitation interaction in changing climate. 

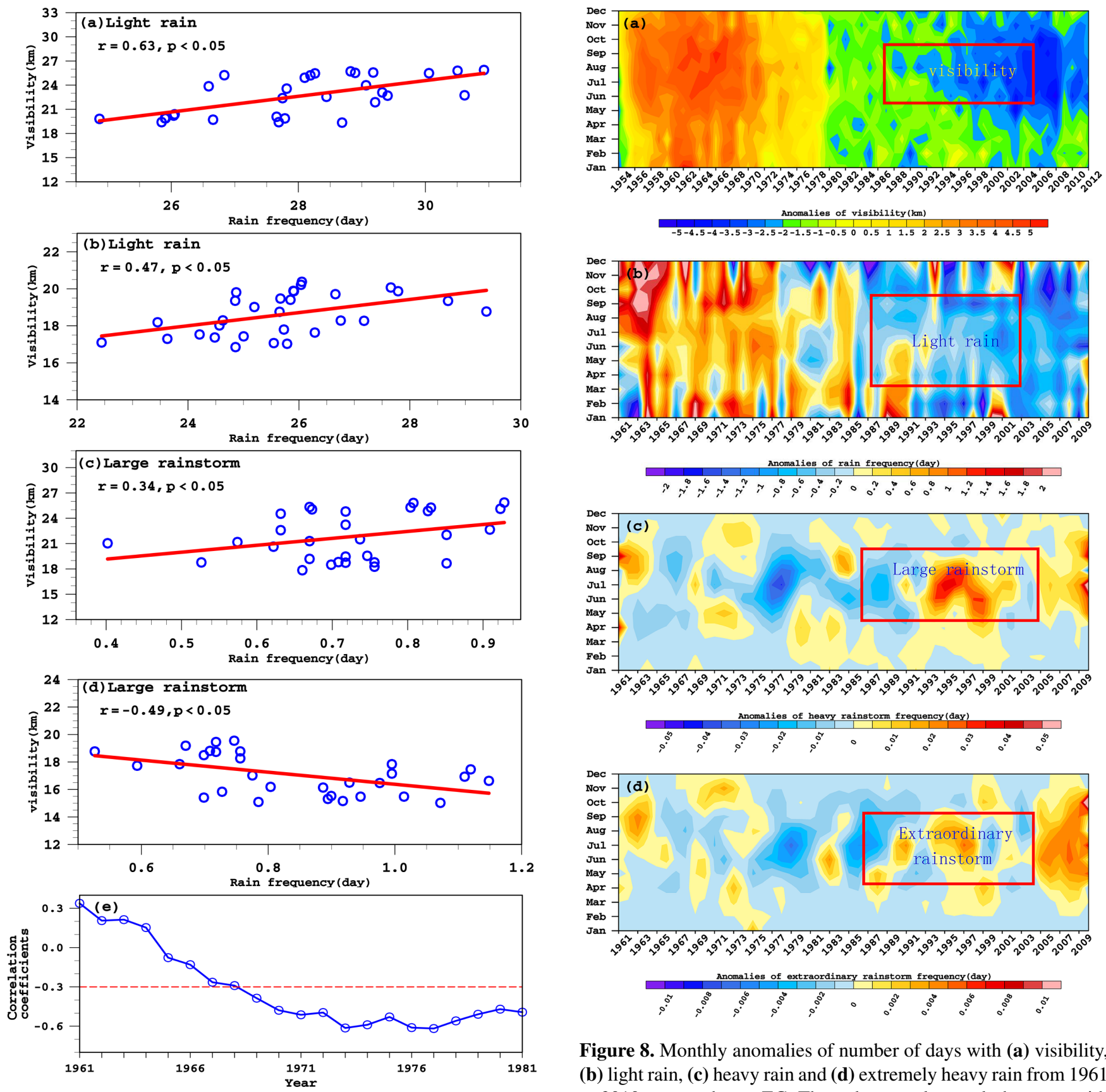

Figure 8. Monthly anomalies of number of days with (a) visibility, (b) light rain, (c) heavy rain and (d) extremely heavy rain from 1961 to 2010 averaged over EC. The red rectangles mark the areas with significant changes.

Figure 7. Correlation between summer average visibility (JuneAugust) with light rain frequency (a) in 1961-1990, (b) light rain frequency in 1981-2010, (c) extremely heavy rain event frequency in 1961-1990 and (d) extreme heavy rain event frequency in 19812010; (e) the 20-year running correlation coefficients of visibility and precipitation over EC with a dashed line standing for when the correlation passes the confidence level of $90 \%$.

In order to investigate the interannual variations in monthly correlation pattern between regional visibility with light rain and extreme precipitation events in EC, we illustrated the cross section of monthly anomalies of visibility

and number of days with light rain and rainstorms, in Fig. 8 . Through a comprehensive comparison of Fig. 8a-d, we could find significant positive correlation between visibility and light rain, indicating that the poor visibility suppressed light rain frequency. Moreover, there was a significant difference between the changing extreme rainstorm and light precipitation occurrences. The changes in large and extraordinary rainstorm frequency from the 1960s to the 1980s were not as prominent as those during the latter period of the 1990s, dur- 


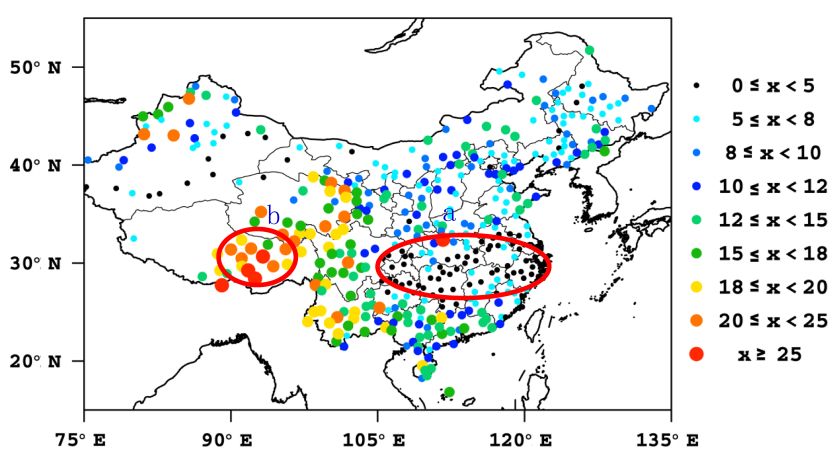

Figure 9. Light rain frequency distribution of 601 stations in China in July of 2013. The circled region on the right is the low-frequency light rain region in the middle and downstream regions in EC, and the circled region on the left is the high-frequency light rain region in the relatively clean region over the TP.

ing which time visibility deteriorated remarkably and heavy and extremely heavy rainstorms occurred frequently. Compared to other seasons, the influence effect of poor summer visibility was more significant in EC, showing disastrous summertime rainfalls happening more often, with less light rain over recent years.

The increased atmospheric aerosol concentration may reduce the solar radiation to the surface and decrease surface temperature, forming a temperature inversion structure (Bollasina et al., 2011; Zhang et al., 2009; Bond et al., 2011, 2013; Grant and van den Heever, 2014; Seinfeld, 2008). This temperature inversion structure with the stability of the atmospheric boundary layer provides an important condition for the frequent occurrence of haze events. The stable low-level structure also inhibits the weak convection development of the atmospheric boundary layer, reducing the formation of low-level clouds and weak precipitation process. However, the strong dynamic convergence disturbance could destroy the stability of the atmospheric boundary layer and cause the formation and development of severe rainstorms.

To further clarify the relationship between aerosols and light rain frequency, the light rain frequency distribution from 601 stations in July 2013 is displayed (Fig. 9). The light rain events have significantly declined in EC with high aerosol concentrations but enhanced in the relative clean TP region (Fig. 9).

To reveal the relationship between aerosols and vertical atmospheric thermal structure, the correlation between surface $\mathrm{PM}_{2.5}$ concentrations and atmospheric thermal structure in both polluted and clean areas in July 2013 was investigated (Fig. 10). The stations of Changsha and Hongjia located in Hunan and Zhejiang provinces in EC, respectively, were selected to represent the less light rain region, while those of Nyingchi and Dingri on the TP were selected to represent the high-frequency light rain region. The correlation coefficient profiles between the observed surface daily $\mathrm{PM}_{2.5}$ concentration and atmospheric temperature profiles derived from high-
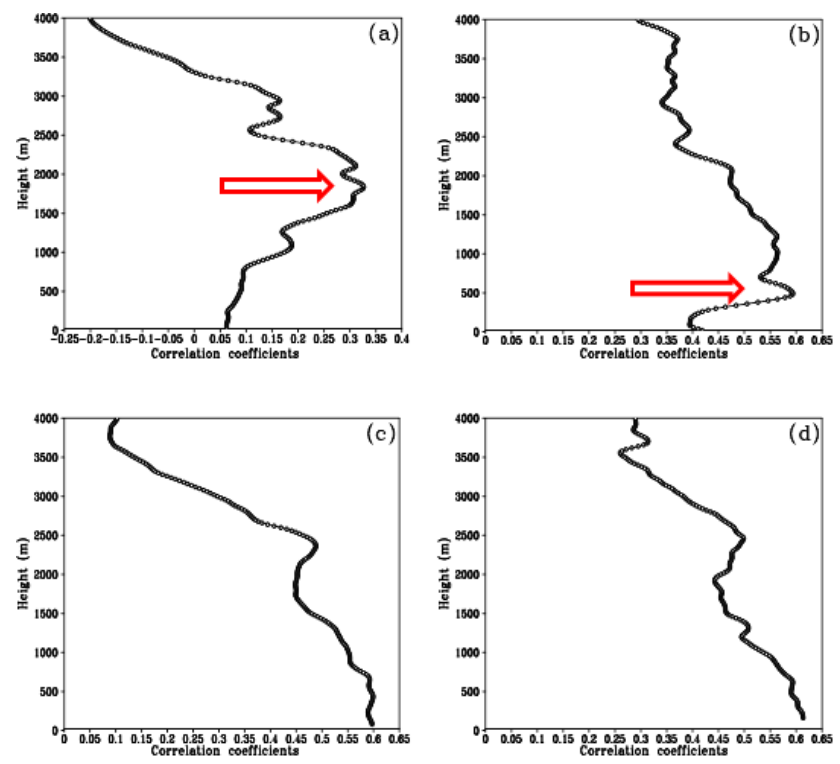

Figure 10. Correlation coefficient profiles between the surface $\mathrm{PM}_{2.5}$ concentration ( $12 \mathrm{~h}$ intervals) and atmospheric temperature from L-band soundings for representing low-frequency light rain regions at stations of (a) Changsha and (b) Hongjia in EC, and for representing high-frequency light rain regions in relatively clean areas at stations in (c) Nyingchi and (d) Dingri over the TP with correlation coefficients of $0.21,0.25$ and 0.32 , passing the confidence level of 90,95 and $99 \%$.

resolution L-band sounding were calculated. The correlations at Changsha and Hongjia stations (Fig. 10a and b) show that the correlation between $\mathrm{PM}_{2.5}$ and temperature profiles presented an inverse phase pattern, reflecting the high aerosol concentrations in a thermal stable structure similar to temperature inversion layers, with cold at low layers and warm at upper layers in EC. Conversely, the correlations at the Nyingchi and Dingri stations on the TP (Fig. 10c and d) indicate that an unstable atmospheric structure with warm at low layers and cold at upper layers is a favorable condition for the occurrence and development of convection and light rain events in the TP.

\section{Physical connection between aerosols and precipitation}

According to the results of observation and modeling studies, increased aerosol concentrations could reduce effective particle radius and increase number concentration of cloud droplets (Khain et al., 2005; Van den Heever et al., 2006; Tao et al., 2007; Altaratz et al., 2014). The increase in cloud droplet concentrations would delay raindrop formation, thereby lessening light precipitation (Qian et al., 2009) for a negative correlation between aerosols and light precipitation in China (Choi et al., 2008). 

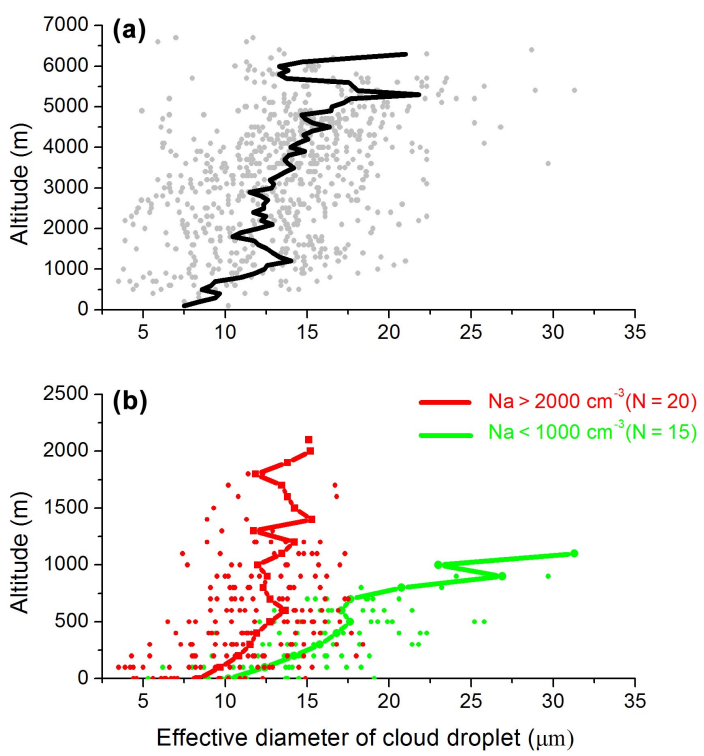

Figure 11. The vertical profiles of (a) sampling cloud droplet size detected by 40 aircraft, and (b) changes in number of diameters of cloud droplets under low and high aerosol number concentrations.

In order to further confirm the relationship between aerosols and cloud droplets, the cloud droplet data observed by aircraft in northern China during 2008-2010 were used. The vertical profiles of cloud droplets under different aerosol states obtained by 40 aircraft are shown in Fig. 11. The Albrecht cloud lifetime effect of aerosols was significant in northeastern China (Fig. 11a and b). Under the background of high aerosol concentrations, the cloud droplet sizes were smaller and increased slowly with the increasing altitude (red profile in Fig. 11b). In addition, from the cloud base to $2000 \mathrm{~m}$, the cloud droplet size remained less than $20 \mu \mathrm{m}$ (Fig. 11b), resulting in precipitation delay, and cloud system development, easily forming heavy rain. Cloud droplet diameter enlarged quickly with the increase in height and easily reached $30 \mu \mathrm{m}$ to form light rain at $1000 \mathrm{~m}$ altitude under low aerosol concentrations (green profile in Fig. 11b). The aircraft observation analysis showed that high aerosol concentrations could reduce cloud droplet size, increase cloud droplet concentrations and extend cloud lifetime, which could all restrict the light rain process.

\section{Discussion and conclusions}

Aerosols have complicated effects on clouds and precipitation, depending on many factors such as aerosol properties, topography and meteorological conditions. Most previous investigations of aerosol impacts on clouds and precipitation are primarily based on limited cases on relatively small spatial and temporal scales. The climate forcing of aerosols on precipitation in large-scale regions and physical causes remain uncertain. By using precipitation and visibility data from more than 50 years and aircraft and surface aerosol data from recent years in China, the impacts of aerosol variations on interannual variability in various precipitation intensities of precipitation events and their physical causes are investigated.

Accompanied with the frequent haze events in EC, the light rain frequency trend significantly decreased. Especially since the 1980s, extremely heavy precipitation events have occurred more frequently, with an obvious transform from more light rain to more frequent heavy rain and rainstorms. In the 1960s, the monthly visibility and light rain presented a significantly positive correlation, while the visibility was in good condition. In the last 30 years, dramatically increased aerosols resulted in poor visibility, light rain frequency decreased obviously, and heavy and extremely heavy rain occurred more frequently.

The investigation of the relationship between aerosol concentrations and light rain frequency distributions in July 2013 in China shows that the light rain appeared significantly low in frequency in the EC region with high aerosol concentrations, but appeared with a high frequency in the relatively clean region of the Tibetan Plateau. High aerosol concentrations were strongly correlated to low-level atmospheric warming, forming a stable structure that suppressed the occurrence and development of light rain events in EC. The aircraft measurements over EC confirmed that the diameters of cloud droplets decreased under high aerosol concentration conditions, thereby inhibiting weak precipitation processes.

The findings from this study have important implications for aerosol and precipitation interactions. The frequent haze events in EC not only cause regional environmental deterioration but also induce long-term change in regional water cycle, which effects regional climate change.

Data availability. No data sets were used in this article.

Competing interests. The authors declare that they have no conflict of interest.

Acknowledgements. This study was supported by the National Natural Science Foundation of China (91644223), the National Key R\&D Program Pilot Projects of China (2016YFC0203304 and 2016YFC0203305), and the project for environmental protection (201509001) in the public interest.

Edited by: Aijun Ding

Reviewed by: two anonymous referees 


\section{References}

Altaratz, O., Koren, I., Remer, L. A., and Hirsch, E.: Review: Cloud invigoration by aerosols-coupling between microphysics and dynamics, Atmos. Res., 140-141, 38-60, 2014.

Bollasina, M. A., Ming, Y., and Ramaswamy, V.: Anthropogenic aerosols and the weakening of the South Asian summer monsoon, Science, 334, 502-505, 2011.

Bond, T. C., Doherty, S. J., Fahey, D. W., Forster, P. M., Berntsen, T., Deangelo, B. J., Flanner, M. G., Ghan, S., Kärcher, B., and Koch D.: Bounding the role of black carbon in the climate system: A scientific assessment, J. Geophys. Res., 118, 5380-5552, 2013.

Bond, T. C., Zarzycki, C., Flanner, M. G., and Koch, D. M.: Quantifying immediate radiative forcing by black carbon and organic matter with the Specific Forcing Pulse, Atmos. Chem. Phys., 11, 1505-1525, https://doi.org/10.5194/acp-11-1505-2011, 2011.

Che, H. Z., Zhang, X. Y., Yang, Y., Zhou, Z. J., Qu, J. J., and Hao, X. J.: Haze trends over the capital cities of 31 provinces in China, 1981-2005, Theor. Appl. Climatol., 97, 235-242, 2009.

Choi, Y. S., Ho, C. H., Kim, J., Gong, D. Y., and Park, R. J.: The impact of aerosols on the summer rainfall frequency in China, $\mathrm{J}$. Appl. Meteorol. Clim., 47, 1802-1813, 2008.

Fan, J., Leung, L. R., Rosenfeld, D., Chen, Q., Li, Z., Zhang, J., and Yan, H.: Microphysical effects determine macrophysical response for aerosol impacts on deep convective clouds, P. Natl. Acad. Sci. USA, 110, E4581-E4590, 2013.

Fan, J., Rosenfeld, D., Yang, Y., Zhao, C., Leung, L. R., and Li, Z.: Substantial contribution of anthropogenic air pollution to catastrophic floods in southwest China, Geophys. Res. Lett., 42, 6066-6075, 2015.

Grant, L. D. and van den Heever, S. C.: Microphysical and dynamical characteristics of low-precipitation and classic supercells, J. Atmos. Sci., 71, 2604-2624, 2014.

Guo X. L., Fu, D. H., Guo, X., and Zhang, C. M.: A case study of aerosol impacts on summer convective clouds and precipitation over northern China, Atmos. Res., 142, 142-157, https://doi.org/10.1016/j.atmosres.2013.10.006, 2014.

IPCC: In Summary for Policymakers, in: Climate Change 2007: The Physical Science Basis, Contribution of Working Group I to the Fourth Assessment Report of the Intergovernmental Panel on Climate Change, Cambridge University Press, Cambridge, 1-18, 2013.

Khain, A. P., Rosenfeld, D., and Pokrovsky, A.: Aerosol impact on the dynamics and microphysics of deep convective clouds, Q. J. Roy. Meteorol. Soc., 131, 2639-2663, 2005.

Lau, K. M. and Wu, H. T.: Detecting trends in tropical rainfall characteristics, 1979-2003, Int. J. Climatol., 27, 979-988, 2007.

Li, Z., Niu, F., Fan, J., Liu, Y., Rosenfeld, D., and Ding, Y.: Longterm impacts of aerosols on the vertical development of clouds and precipitation, Nat. Geosci., 4, 888-894, 2011.

Qian, W., Fu, J., and Yan, Z.: Decrease of light rain events in summer associated with a warming environment in China during 1961-2005, Geophys. Res. Lett., 34, L11705, https://doi.org/10.1029/2007GL029631, 2007.
Qian, Y., Gong, D. Y., Fan, J. W., Leung, L. R., Bennartz, R., Cheng, D. L., and Wang, W. G.: Heavy pollution suppresses light rain in China: Observations and modeling, J. Geophys. Res., 114, D00K02, https://doi.org/10.1029/2008JD011575, 2009.

Rosenfeld, D., Dai, J., Yu, X., Yao, Z., Xu, X., Yang, X., and Du, C.: Inverse relations between amounts of air pollution and orographic precipitation, Science, 315, 1396-1398, 2007.

Rosenfeld, D., Lohmann, U., Raga, G. B., O’Dowd, C. D., Kulmala, M., Fuzzi, S., Reissell, A., and Andreae, M. O.: Flood or drought: How do aerosols affect precipitation?, Science, 321, 1309-1313, 2008.

Seinfeld, J.: Atmospheric science: Black carbon and brown clouds, Nat. Geosci., 1, 15-16, 2008.

Stevens, B. and Feingold, G.: Untangling aerosol effects on clouds and precipitation in a buffered system, Nature, 461, 607-613, 2009.

Tao, W. K., Li, X., Khain, A., Matsui, T., Lang, S., and Simpson, J.: Role of atmospheric aerosol concentration on deep convective precipitation: Cloud-resolving model simulations, J. Geophys. Res., 112, D24S18, https://doi.org/10.1029/2007JD008728, 2007.

Van den Heever, S. C., Carrió, G. G., Cotton, W. R., DeMott, P. J., and Prenni, A. J.: Impact of nucleating aerosol on Florida storms Part I: Mesoscale simulations, J. Atmos. Sci., 63, 1752-1775, 2006.

Wang, Y. and Zhou, L.: Observed trends in extreme precipitation events in China during 1961-2001 and the associated changes in large-scale circulation, Geophys. Res. Lett., 23, L09707, https://doi.org/10.1029/2005GL022574, 2005.

Wang, K., Dickinson, R. E., and Liang, S.: Clear sky visibility has decreased over land globally from 1973 to 2007, Science, 323, 1468-1470, https://doi.org/10.1126/science.1167549, 2009.

Xia, X. A., Wang, P. C., Chen, H. B., and Liang, F.: Analysis of downwelling surface solar radiation in China from National Centers for Environmental Prediction reanalysis, satellite estimates, and surface observations, J. Geophys. Res., 111, 2105-2117, https://doi.org/10.1029/2005JD006405, 2006.

Xu, X., Zhao, T., Liu, F., Gong, S. L., Kristovich, D., Lu, C., Guo, Y., Cheng, X., Wang, Y., and Ding, G.: Climate modulation of the Tibetan Plateau on haze in China, Atmos. Chem. Phys., 16, 1365-1375, https://doi.org/10.5194/acp-16-1365-2016, 2016.

Zhai, P. M., Ren, F. M., and Zhang, Q.: Detection of trends in China's precipitation extremes, Acta Meteorol. Sin., 57, 208$215,1999$.

Zhang, H., Wang, Z. L., Guo, P. W., and Wang, Z. Z.: A modeling study of theeffects of direct radiative forcing due to carbonaceous aerosol on the climate in East Asia, Adv. Atmos. Sci., 26, 57-66, 2009.

Zhao, T., Liu, D., Zheng, X., Yang, L., Gu, X., Hu, J., Shu, Z., Chang, J., and $\mathrm{Wu}, \mathrm{X}$.: Revealed variations of air quality in industrial development over a remote plateau of Southwest China: an application of atmospheric visibility data, Meteorol. Atmos. Phys., 1-9, https://doi.org/10.1007/s00703-016-0492-7, 2016. 